\title{
Para o bem e para o mal: a despolitização da política externa brasileira e a politização das tradições
}

\author{
For good or evil: the depoliticization of Brazilian foreign policy and \\ the politicization of traditions
}

\section{Lucas Ribeiro Mesquita}

\section{Resumo}

O artigo busca compreender o papel político das tradiçóes diplomáticas no contexto da política externa brasileira. Trabalhando com a hipótese de que a tradição diplomática brasileira é utilizada ao longo da história de duas maneiras bem distintas, variando de acordo com os interesses de apropriação dos grupos. Em primeiro lugar, quando apropriada por aqueles que compóem o governo a tradiçáo serve como recurso para despolitização da política externa brasileira, ao servir de elemento justificador das escolhas políticas, em contrapartida os grupos de oposição recorrem à tradição e ao questionamento da sua permanência nas escolhas políticas para politizar as escolhas internacionais do governo, nesse sentido, politizar a tradição serve como mecanismo de contestação política. À guisa de conclusão, a observação permite o entendimento de que aqueles que buscaram interferir no debate da política via utilização das tradições, o fizeram de acordo com seus propósitos políticos dentro de duas chaves possíveis.

\section{Palavras-chave}

Tradição; Política Externa Brasileira; Itamaraty.

\begin{abstract}
The article seeks to understand the political role of diplomatic traditions in the context of Brazilian foreign policy. Working with the hypothesis that the Brazilian diplomatic tradition is used throughout history in two distinct ways, varying according to the interests of groups. Firstly, when appropriated by those who make up the government, tradition serves as a resource for depoliticization of Brazilian foreign policy, serving as justification for policy choices. However, opposition groups resort to tradition and to the questioning of the performance of policies to politicize international choices of government serving as, in this sense, politicizing the tradition of political contestation mechanism. In conclusion, the observation supports the compreension that those who sought to interfere in the political debate through the use of traditions, made it according to their political purposes.
\end{abstract}

\section{Keywords}

Tradition; Brazilian Foreign Policy; Itamaraty. 


\section{Introdução}

Se formos atrás de consensos na literatura sobre o Ministério de Relaçóes Exteriores (MRE) um que certamente será invocado é o da capacidade de se manter ao longo do tempo como uma unidade coesa, coerente e com uma estabilidade institucional como poucas burocracias nacionais. $\mathrm{O}$ grande trunfo, a nosso ver, dessa capacidade institucional do Itamaraty de perdurar como estrutura coesa, sustentando uma identidade ao longo de vários regimes e sistemas políticos nacionais é a força e o papel político e social da tradição.

O adjetivo tradicional, de acordo com Mariano (2007), reforça o reconhecimento de que a ação diplomática brasileira é singular, e ao mesmo tempo, dotada de padrão geral capaz de se ajustar as circunstâncias dominantes da época, adaptação que contribui para a continuidade e para a maior previsibilidade da política externa.

Nesse sentido, o Itamaraty mantém sua coesão, estabilidade e identidade não somente através da atualização de símbolos, signos e ritos, mas também pela criação e manutenção de um conjunto de ideias que por consequência permitem que a instituição apresente uma memória institucional, a qual é constantemente renovada e reutilizada de inúmeras maneiras (BUERE, 2011).

Muitas vezes em função de se projetar como uma instituição coesa, o MRE se blinda de demonstrar para a sociedade suas divisóes internas, deixando-as cair em esquecimento institucional. O processo de consolidação de uma tradição "vencedora", porém, não se constrói sem os embates políticos característicos de uma instituição que agrega interesses e projetos múltiplos.

O que confere a coesão é em grande parte a reafirmação da tradição, por isso o processo de produção das tradiçóes, e seu uso como justificativa política não deve ser tratado sem perceber o caráter político por de trás das ações de construção institucional, mas pelo contrário,

[...] a definição do que se lembrará e o que se esquecerá é feita no meio das lutas políticas acerca de qual deverá ser o caráter da instituição, o que deverá ser destacado, resgatado, modificado ou renegado. E esta atividade tem relação direta com a complexidade da instituição que a produz; assim, quanto mais hierarquizada e competitiva, mais essa memória retornará aos pais fundadores e aos heróis da fundação - de fato ou simbólicos - da instituição. É, portanto, com base em projetos políticos do presente - que, por sua vez, estão relacionados com as barganhas políticas contemporâneas - que as memórias e, com elas, as identidades são construídas (FRANCISCO, 2010, p. 20). 
O processo de construção da imagem do Ministério, nesse sentido, pode ser pensado como um processo baseado em uma dicotomia, a saber: fortalecimento do projeto dominante, e esquecimento do projeto concorrente. Como sugere Douglas (1998),

[...] as instituiçóes criam lugares sombreados no qual nada pode ser visto e nenhuma pergunta pode ser feita. [...] A história surge como uma forma não-intencional, como resultado de praticas direcionadas a fins imediatos, práticos (DOUGLAS, 1998, p. 76).

Os relatos de Almeida (2008) permitem ilustrar os grandes embates de interesses que estiveram presentes no MRE, os quais reverberavam os grandes conflitos de interesses da sociedade e do Estado brasileiro. Segundo o diplomata, dentro da história do Itamaraty sempre houve confrontos de ideias e de acomodaçôes pragmáticas entre os partidários de diferentes correntes de opinião que perpassam e dividem a agência diplomática, como de resto sempre foi o caso com diversas outras instituições do Estado e com a própria sociedade brasileira.

Embates dicotômicos não foram raros na moderna história brasileira, colocando pessoas e grupos que defendiam posiçóes antagônicas na agenda política em confronto direto, redistribuindo cartas nos jogos de poder que inevitavelmente acompanham esses enfrentamentos e provocando cisóes na elite - e apenas na elite como resultado desses confrontos, de resto mais ruidosos do que verdadeiramente ruinosos, mais ideológicos do que materiais, num país bem mais propenso à conciliação do que à ruptura.

Retomar a discussáo sobre a formação das tradiçóes diplomáticas brasileiras no momento se justifica, principalmente, pelo embate vivenciado pela diplomacia brasileira acerca de um suposto enviesamento ideológico da política externa nos últimos governos, o qual teria ruído o consenso da diplomacia brasileira arraigada na tradição institucional.

Essa tradição institucional, porém, não é resultado de um rápido processo. A tradição brasileira em política externa se consolidou, e foi construída ao longo de um processo histórico, em duas linhas principais: pelo fortalecimento da memória institucional pelo próprio Itamaraty, que durante a história foi responsável pela mitificação de criação de personagens e mitos influentes na ação diplomática brasileira, e pela própria retificação por parte da academia desses preceitos tradicionais.

Para Francisco (2010, p. 11) é a tradição que mantém a coesão e a unidade do Itamaraty, que (teoricamente) confere uniformidade ao pensamento e a formação de 
seus membros, e muitas vezes, é também a tradição que explica os rumos e as decisões da Política Externa Brasileira (PEB).

Entretanto, qual seria o papel da tradição diplomática nas disputas e nos discursos políticos relacionados à temática? Através da proposta metodológica da narrativa histórica, utilizando de discursos e textos produzidos por peças-chave da política externa brasileira durante o período analisado, trabalhamos com a hipótese a seguir tentaremos apontar algumas reflexóes sobre o tema: durante os quase duzentos anos da história diplomática brasileira a tradição é utilizada de duas formas bem distintas, a depender dos interesses de apropriaçáo dos grupos em disputa. Por um lado, quando apropriada por aqueles que compóem o governo a tradição serve como recurso para despolitização da política externa brasileira, ao servir de elemento justificador das escolhas políticas. Pelo outro lado, e em contrapartida, os grupos de oposição recorrem à tradiçáo e ao questionamento da sua permanência nas escolhas políticas para politizar as escolhas internacionais do governo, nesse sentido, politizar a tradição serve como mecanismo de contestação política.

A seguir apresentaremos nossa discussão sobre a temática, sem intenção exaustiva, dividindo o artigo em quatro partes para além da introdução. A primeira parte apresenta a discussão acerca da formação das tradições diplomáticas brasileiras, para em seguida compreender como ela foi se consolidando, principalmente em função da valorização das práticas de Rio Branco. A quarta parte busca apresentar como ao longo da história a invocação das práticas tradicionais serviu como prática política por diversos grupos e atores. Por fim, tecemos breves conclusóes.

\section{A Formação da Tradição}

O Itamaraty, em seus primórdios, fora o lugar da grande elite intelectual brasileira, sendo o lócus da aristocracia republicana (LOPES, 2011), no qual foram "preferidos os bacharéis formados nos cursos jurídicos do império, e os graduados em academias ou universidades estrangeiras, que mais versados se mostrarem em línguas" (SOARES, 1984, p.53).

Essas peculiaridades permitiram que a Casa de Rio Branco se confirmasse como um local de destaque dentro da estrutura política nacional, o que de acordo com Lopes (2011) permitiu que os membros da elite bien pensant brasileira do século XIX tivessem sido autorizados (ou se sentissem credenciados) a interpretar o interesse nacional (isto é, o que se entendia por "bem comum") em nome da coletividade pátria, tendo por parâmetros os próprios padróes intelectuais e morais, individuais e coletivos. 
A construção da memória institucional itamaratiana, pode ser pensada como a estratégia fundadora dessa tradição. Goffredo Jr. (2000), utilizando das premissas de Cheibub (1984) argumenta que

[...] devido ao alto grau de profissionalismo e ao esprit de corps dos diplomatas, coube a eles tomar a liderança no que se refere não apenas à execução, mas também à formulação da política exterior do país durante quase todo o período republicano. Surge entáo a categoria dos "operadores/formuladores" que dialogam com elementos da "tradição" para conceber a política externa do país de acordo com as contingências do momento histórico em que vivem. Não raro, esses indivíduos vão buscar nos princípios históricos da diplomacia o sustento para dar legitimidade à posição brasileira (GOFFREDO JR., 2000, p. 95).

O modelo de construção da memória institucional invocada pela política externa se aproxima das concepçóes teóricas sobre o processo de formação das tradiçóes e da memória social. Essa linha teórica considera que a memória possui a função de promover uma identidade coletiva entre os membros de determinado grupo com base em seu passado coletivo, conferindo certa imutabilidade, ao mesmo que tempo que cristaliza os valores predominantes do grupo (HALBWACHS, 1997). Dentro da consideração sobre o uso do passado como elemento político, Misztal (2003) defende que os elementos do passado são estrategicamente inventados e manipulados de acordo com as necessidades do presente, conforme os propósitos políticos instituídos.

Essa aproximação teórica se aproxima em muito da perspectiva de Eric Hobsbawn (1997), no qual as tradições surgem e se estabelecem na vida pública através da repetição, o que implica, automaticamente, uma continuidade em relação ao passado. Para o autor o conceito se define como um conjunto de práticas reguladas por regras tácitas ou abertamente aceitas, tais práticas, de natureza ritual ou simbólica, visam inculcar certos valores e normas de comportamento através da repetição, o que implica, automaticamente, uma continuidade em relação ao passado Hobsbawn (1997).

Em concordância com Francisco (2010), os exemplos da política externa apontam para fato de que a tradição pode atuar tanto como conceito no discurso político quanto como categoria analítica. Como é sugerido, as tradições da política são tradiçóes inventadas, para utilizar o termo de Hobsbawn (1997), porém, o processo de consolidação da tradição "itamaratiana" deve ser pensada como um processo de resgate de certas tradiçóes, os seja, a justificativa de projetos podem 
remeter as forças profundas (RENOUVIN e DUROSELLE, 1967) que regem a política externa, na busca pela legitimidade necessária para ser colocada em prática.

Segundo Francisco (2010) as "forças profundas" têm o potencial, assim, de tornar-se uma categoria analítica justificadora da leitura da história da política exterior brasileira como um sistema baseado em padrões de generalizaçôes que comportam permanência e rupturas. De acordo com a autora, a açáo do Itamaraty, desde a sua fundação, pode ser caracterizada pelo distanciamento ou pela aproximação na leitura do que propóe tal força profunda pelos homens de Estado e membros da instituiçáo diplomática, o que possibilita o resgate e a defesa de projetos políticos, os quais adquirem status de atemporalidade e de ausência de contingência quando inseridos numa narrativa pautada pela ação das forças profundas sobre os homens e por sua organização das dinâmicas históricas.

Dentro dessa lógica, trabalharemos com o pressuposto de que a política externa brasileira foi formada como resultado de um processo de construção de tradiçôes diplomáticas ao longo da história imperial e republicana. A forte tradição da política externa explicitada na figura do Barão de Rio Branco e das medidas de coesão institucional do Ministério, construídas sob os princípios basilares da política interna brasileira do século XIX, formaram ao longo da república a imagem de coesão do Ministério, essa sendo projetada para a sociedade.

Ao trazermos o foco para a discussão do papel da tradição para a formação da coesão do Itamaraty, evidenciamos algo que não fora muito salientado pela literatura, e que de certa forma contradiz a máxima da coesão do pensamento interno da instituição: as disputas existentes dentro da própria instituição em relação às propostas da política externa brasileira.

Cabe perceber que a despeito da projeção de fortes amarras institucionais na história brasileira as disputas internas existiram no MRE, e nesse sentido buscaremos a resposta para a existência de diferentes projetos existentes na própria instituição. Partimos, portanto, do pressuposto de que embora sejam fortes as tradições, seus padrôes de recorrência e seus mecanismos de institucionalização, essas não impedem que o pensamento acerca da política externa brasileira seja coeso e unitário.

Acreditamos que os elementos tradicionais que o Itamaraty consegue manter como tradição da política externa, são reconstruídos ao longo da historia e utilizados com diferentes propósitos sobre a inserção internacional do país, diferenças essas formuladas em função do acesso ao poder decisório por diferentes projetos políticos, e em consequência pela utilização dos constrangimentos institucionais. 


\section{Consolidação da Tradição no MRE}

Para compreender como as tradições diplomáticas se consolidaram é necessário invocarmos as práticas e ritos, que foram responsáveis por tornar o Itamaraty um suposto exemplo de coesão, para tal devemos resgatar, em especial, a figura de Barão de Rio Branco. Nossa empreitada de reconstruir a formação da arca das tradiçôes da política externa brasileira não se completa sem elucidarmos os outros dois importantes founding fathers do tradicionalismo diplomático brasileiro, Rui Barbosa e Joaquim Nabuco.

Foquemos inicialmente na visão mais antropológica da consolidação das tradições itamaratianas. A análise dos rituais e práticas do Itamaraty nos permite ter uma visão privilegiada do processo de construção de tradições, dado que o domínio dos rituais de uma instituição permite a penetração "no cultural de uma sociedade, na sua ideologia dominante e no seu sistema de valores" (DAMATTA, 1997, p. 29).

Como elucida DaMatta (1997), o domínio dos ritos e das formulas que inventam e sustentam personagens culturais é a esfera daquilo que gostaríamos que estivesse situado ao longo ou mesmo fora do tempo, devido a tal, os rituais servem, sobretudo em uma sociedade complexa, para promover a identidade social e promover seu caráter.

Segundo Moura (2007), o corpo diplomático brasileiro é uma coletividade que se define em termos profissionais através da noção de carreira e de categoria funcional, e um grupo de status que se distingue por um ethos e uma visão de mundo compartilhado. A auto representação do grupo é feita através de imagens que remetem à formação de um parentesco "diplomático, na qual a coletividade dos diplomatas se pensa através das metáforas biológicas, de parentesco e de relações domésticas, e a grande imagem que remete ao patriarca e patrono da Casa é o Barão de Rio Branco" (MOURA, 2007, p.109). 
Para pensarmos Rio Branco hoje, é necessário termos em conta que esse nome é o principal recurso simbólico através do qual os diplomatas brasileiros pensam suas carreiras, sua instituição e a relação destas duas com a construção nacional. Rio Branco está presente em forma de bustos espalhados pelo Palácio Itamaraty em Brasília e no Rio, dá nome à ordem honorífica da diplomacia brasileira, empresta seu aniversário ao Dia do Diplomata, quando, após o Hino Nacional, se toca o Dobrado de Rio Branco, nomeia o Instituto responsável pela formação dos diplomatas brasileiros e, finalmente, intitula a própria instituição, que se autodenomina Casa de Rio Branco, em uma metáfora que invoca relaçóes de parentesco dinásticas. Rio Branco é, assim, sinônimo da tradição na diplomacia brasileira, que se distingue por um ethos específico (MOURA, 2000, p. 82).

A invenção das tradiçóes (HOBSBAWN, 1997) diplomáticas brasileiras foi baseada, segundo Moura (2000 e 2007), na reprodução dos mitos, rituais, padrôes de socialização da vida e da carreira diplomática, associada sempre a figura de Rio Branco, os quais procuraram consolidar a figura do personagem como o marco fundador da linhagem diplomática.

O interessante é perceber como as tentativas de relacionar a tradição à figura de Rio Branco são utilizadas pela burocracia para a manutenção da tradição de coesão interna e do caráter central na produção política. Para tal, são utilizados dois mecanismos, a reprodução via biografias do caráter mítico do personagem e a sua associação ao legado do modo de produção da política externa.

As palavras do chanceler Fernando Henrique Cardoso, em discurso nas comemorações do Dia do Diplomata reforçam a ideia.

[Esta] cerimônia traz, como qualquer ritual, conotações de tradição e renovação. Tradição, porque a diplomacia está ancorada na história. Nutre-se de ensinamentos do passado e da experiência de tantos servidores que engrandeceram o seu nome, muito deles ilustres homens públicos e estadistas, a começar por aquele que é seu patrono, Rio Branco (CARDOSO, 1993, p.1).

A narrativa mítica em torno do Barão de Rio Branco é geralmente fundada em torno da sua representação como um emblema de uma coletividade, materializado em estátuas e medalhas que acabam sendo portadoras de certa sacralidade, mas que encontra nas biografias a principal fonte de "mitificação" (MOURA, 2000).

As narrativas biográficas, segundo Moura (2000), são importantes ferramentas da construção do caráter impenetrável da personalidade do mito, na qual é retratado 
o personagem como possuidor de uma trajetória única passível de ser biografada, principalmente a partir de sua carreira profissional. De acordo com Velho (1994 apud MOURA, 2000),

[...] a trajetória do indivíduo passa a ter um significado crucial como elemento não mais contido mas constituidor da sociedade. [na qual] [...] carreira, biografia e trajetória constituem noçôes que fazem sentido a partir da eleição lenta e progressiva que transforma o indivíduo biológico em valor básico da sociedade ocidental moderna (VELHO, 1994 apud MOURA, 2000, p. 83).

Essa narrativa de consolidação da figura de Rio Branco compreende, segundo Francisco (2010), uma série de manifestações com o fim de consolidar esse personagem como o inicio da árvore genealógica da "família" Itamaraty, no qual se ressalta o papel estadista de Rio Branco, afinal essa narrativa se constrói principalmente na ideia de que o Barão foi além do que se esperava de um executor, ele conseguiu visualizar a atingir os interesses nacionais e realizá-los sem participar do ambiente auto-interessado da política interna, sem participar das disputas políticas e jogo de interesses, feito compreensível porque o Barão foi um retraído político e um homem de estudo, mais afeito aos gabinetes de leitura do que aos ministeriais.

Essa construção institucional remete e reforça a definição dos diplomatas como os detentores legítimos da definição do interesse nacional, e do caráter central do Itamaraty na formulação da política externa. A herança que Rio Branco deixou aos seus discípulos teria sido o legado de como se fazer política externa, o qual se definiria com uma aproximação indiscutível com as práticas imperiais de se fazer política. Segundo Francisco (2010), o legado se caracterizaria por

[...] não permitir que esta se transforme em uma função das ambiçóes e interesses particulares e não subordinar o Ministério das Relaçóes Exteriores a mudanças de presidentes, com o objetivo único de trabalhar para consolidar os interesses maiores do Estado brasileiro (FRANCISCO, 2010, p. 72).

Para além da manutenção do modus de produção, a narrativa em torno do Barão evidencia a construção da coesão interna, uma vez que o legado dele será sempre recontado e, assim, atualizado a partir de uma perspectiva interessada em determinado enquadramento de uma de suas faces, na qual o questionamento da figura e dos seus atos remete a uma postura iconoclasta (ALMEIDA, 1996; FRANCISO, 2010). 
Francisco (2010) nos ajuda a evidenciar uma parte da nossa hipótese - a da tradição como ferramenta de legitimidade política, ao defender que a tradição em torno de Rio Branco apresenta um caráter múltiplo (monarquista, diplomata, intelectual, chanceler, estadista o qual permite ser caracterizado de acordo com a versão da história que se quer contar, mantendo sua atualidade).

Ainda Francisco (2010) postula que a "atualidade" do modelo supostamente desenvolvido pelo Barão é construída pelos atores que têm poder sobre o processo de elaboração da memória institucional do Itamaraty, do qual o personagem Barão do Rio Branco é certamente o protagonista do enredo a ser transmitido como "tradiçáa" o que permite, por exemplo, associar opçóes de política externa a imagem do Barão como ferramenta de legitimação, uma vez que esse representa na sua essência a precedência do estadista, e toda representação que se constrói por trás do conceito, em relação ao político.

Rio Branco, de fato, ajudou a consolidar as tradiçóes da política externa brasileira, principalmente às referentes, ao pacifismo, ao juridicismo, a igualdade jurídica entre os Estados e a preferência americana. A importância dele permitiu que tais práticas fossem incorporadas ao acervo permanente, conferindo "um traço de continuidade e coerência sempre invocado pelo Itamaraty como um trunfo em sua atuação internacional" (SILVA, 1999, p. 98).

Ao mencionar a consolidação dos princípios juridicistas, pacifistas e de igualdade soberana, é inevitável tratar da obra de Rui Barbosa e de sua atuação como plenipotenciário brasileiro na Segunda Convenção de Haia de 1907. Em Haia, pela primeira vez na história, nações independentes latino americanas participavam de uma discussão no âmbito das high politics internacionais, com uma agenda principal voltada para a discussão sobre a criação de uma Corte de Justiça Arbitral.

A política externa brasileira na época da Conferência, segundo o próprio chanceler Rio Branco (CARDIM, 2007), se encontrava defasada aos acontecimentos mundiais em função, principalmente, do histórico movimento que a elite política responsável pela condução da pasta de Negócios Internacionais delegou a superação das questóes da independência, da questão sulamericana. Nesse sentido, a política externa precisava se reorientar sob as novas condiçóes do sistema internacional. A Conferência de Haia seria o primeiro espaço no qual a política externa expressaria essa nova configuração de ação diplomática.

No decorrer da Conferência, a delegaçáo dos Estados Unidos propôs a criação de uma Corte de Justiça Arbitral a qual, segundo Amorim (2007), seguia o plano das grandes potências de uma representação seletiva dentro da instituição, sem claros critérios consensuais. Justamente em oposição à proposta americana, a figura do 
político Rui Barbosa fez frente, apresentando o desagrado da comitiva brasileira, e apresentando ao mundo, pela primeira vez, as bases que serviriam para consolidar três importantes tradiçóes, a primazia do juridicismo, a igualdade soberana entre as nações e o caráter pacifista da diplomacia nacional.

Segundo Cardim,

a atuação conjunta de Rio Branco e Rui Barbosa inaugura uma nova etapa da diplomacia brasileira e marco o inicio da construção de novos paradigmas na inserção internacional do país, notadamente o paradigmas da igualdade entre as naçóes e o da perspectiva universalista (CARDIM, 2007, p. 89).

Para além do questionamento, a postura de Rui Barbosa na Conferência representou a invocação do princípio da igualdade soberana entre as naçóes. Ao invocá-lo, respaldada no internacional, Rui insistiu "no direito das potências menores de se verem condignamente representadas no projetado tribunal” (AMORIM, 2007, p. 7).

Sobre os resultados da Conferência o estadista discorre questionando se os resultados alcançados ficaram a margem das expectativas, os resultados invisíveis foram mais longe, no sentido que a Conferência mostrou às potências o papel dos países periféricos na elaboração do direito das gentes, adiantou a base da pacificação internacional, evidenciando que, em uma assembléia convocada para paz, não se podem classificar os votos dos Estados em razão de suas capacidades militares, e por fim, revelou ao mundo antigo os novos países, com sua fisionomia, independência e vocação para o direito das gentes (BARBOSA, 1907 apud CARDIM, 2007).

Nessa nova conjuntura, na qual os EUA reformularam a Doutrina Monroe, principalmente sob o signo do pan-americanismo, que as relações interamericanas foram reconduzidas no início do século XX. Segundo Azevedo e Fernandes (2011) se os encontros continentais realizados até então não haviam gerado qualquer comprometimento formal do governo brasileiro, a receptividade ao monroismo e ao pan-americanismo, propalados pelo governo norte-americano, se expressara desde os tempos de D. Pedro I, com o novo regime, buscou-se formular uma visão americana própria.

O Brasil, no intuito de aprofundar o relacionamento com os Estados Unidos, abre sua primeira embaixada em Washington no ano de 1905, sob o comando de Joaquim Nabuco. Mesmo que para Nabuco e Rio Branco os Estados Unidos se configurassem como o centro de um subsistema de poder, a postura brasileira em 
relação ao mesmo deveria ser baseada em uma leitura realista das condiçóes de poder regionais ${ }^{1}$.

A diplomacia brasileira reconhecia o peso estadunidense no sistema internacional, a posição da América Latina como área de influência, e a impossibilidade de se contrabalancear as capacidades dos EUA. Entretanto, utilizava dessa configuração para permitir "jogar com mais desembaraço com seus vizinhos" (CERVO e BUENO, 2002, p. 185), descartando o jogo europeu. Nabuco era o principal crente no sistema continental.

Eu não terminaria se fosse enumerar todo o bem que a América Latina poderia colher de um contato próximo com os Estados Unidos [...] vossa política americana obedece a um profundo instinto continental e não é apenas medida de precaução nacional e de defesa própria (NABUCO, 2010 [1909], p. 32).

De acordo com Cervo e Bueno (2002), Nabuco enxergava a Doutrina Monroe como uma aliança que evitava a cobiça estrangeira no Brasil, ou seja, ela servia para a manutenção da liderança estadunidense na região, mas ao mesmo tempo permitia ao Brasil uma liberdade política em relação à Europa.

Rio Branco deslocou o eixo da política externa brasileira em direção a Washington, segundo Santos (2005), com o uso de gestos simbólicos, como a elevação das respectivas legações ao status de embaixadas e a realização da Terceira Conferência Americana no Rio de Janeiro, e políticas concretas como o reconhecimento da soberania do Panamá, a aprovação tácita do Corolário Roosevelt, a indiferença ante as intervenções estadunidenses na América Central e no Caribe, o repúdio à Doutrina Drago, entre outras.

\section{As duas faces da tradição}

Após uma breve explicação do processo de formação das tradiçốes diplomáticas brasileiras, cabe agora demonstrar o seu uso político ao longo da história diplomática brasileira. Apresentaremos a seguir trechos de discursos, opiniōes e documentos que demonstram o caráter dúbio das tradições, em função da utilização dos elementos tradicionais da política externa por lados com visões e argumentos opostos relativamente à política externa, enquanto argumento para manter ou mudar a política externa.

1 Para uma leitura histórica do processo de formação das relações Brasil e Estados Unidos, sugerimos a obra de Bradford Burns "The Unwritten Alliance" (1966). 
O interessante é perceber que a utilização do questionamento às tradições como instrumento político não é recente. Ao assumir a chancelaria brasileira, Barão de Rio Branco, o founding father da diplomacia nacional, teve seus atos questionados em razão da tradição. De acordo com Cheibub (1984), particularmente em razão das suas discordâncias com o Visconde de Cabo Frio, Rio Branco alterou a hierarquia organizacional do MRE, mudança que alterou toda a estrutura de trabalho na Secretaria de Estado e centralizou toda a administração em torno de sua pessoa de um ministério.

Anteriormente à gestáo Rio Branco, o principal cargo da diplomacia brasileira (CHEIBUB, 1984) estava na função de Diretor Geral da Secretaria de Estado, cargo que tinha na figura de Cabo Frio a manutenção da tradição diplomática imperial, servindo de balança para as frequentes mudanças de Ministros. Com a ascensão de Rio Branco ao cargo de Ministro, a funçáo de Diretor Geral se enfraqueceu, em contrapartida, o Gabinete do Ministro passou a ser o principal órgão decisor, o qual era personificado na figura centralizadora de Rio Branco.

À época as atitudes de Barão de Rio Branco foram questionadas pelos chefes de Seções, que se mostravam contrários às propostas, que no entender desses a postura de Rio Branco representava "a tendência cada vez mais acentuada, da quebra de uns tantos usos e costumes, desmoronando-se pela aparente desordem dos métodos de trabalho e de agir do Barão, ferindo o 'tabu de' ritos e tradições" (AMARAL apud CHEIBUB, 1984, p. 45).

No seu segundo governo, Getúlio Vargas no intuito de justificar sua aliança militar com os Estados Unidos na década de cinqüenta, também buscou legitimar suas ações na tradição, dizendo "[...] que a nossa tradição histórica e os nossos interesses políticos e econômicos nos movem hoje, como nos moveram sempre, a uma política de estreita colaboração com os Estados Unidos da América (VARGAS, 1952, p. 2).

Afonso Arinos e San Tiago Dantas também não abriram mão de invocar as tradições diplomáticas brasileiras. Ambos reafirmavam o respeito às tradiçôes, e Afonso Arinos ensaiava, baseando-se nessas, indícios de mudanças. 
Tradição nós não a rejeitamos, porque lhe conhecemos o sentido e a significação. Ao contrário do conservadorismo, tradição quer dizer, na acepção latina, entrega sucessiva, passagem periódica. Tradição não quer dizer estagnação num período, quer dizer depósito temporário e sucessivo. Honro a tradição do Itamarati, para declarar, explicitamente, que o Itamarati é uma casa de tradição (FRANCO apud FRANCO FILHO, 2001, p. 144, grifo nosso).

Tais ideias, vitoriosas nesta casa e apresentadas pela diplomacia brasileira em todas as oportunidades em que lhe têm sido confiadas missóes, são também as ideias do novo governo de gabinete, que especificamente decidiu reafirmar a continuidade da sua linha política dentro da melhor tradição da democracia brasileira fiel aos nossos ideais, às nossas tradiçôes cristãs, a todos esses valores que formaram a nossa civilização e em defesa dos quais desejamos participar da vida internacional, provocando-os, de- fendendo-os, levando-os a todos os povos pelo valor intrínseco que neles se contém. [...] É o privilégio de uma chancelaria, atingida a maturidade dos seus métodos e a plena definição dos seus objetivos, impor-se ao homem público que é chamado eventualmente a dirigi-la. Aqui venho para ser um intérprete e um servidor dessa tradição (DANTAS, 1961, p. 159, grifo nosso).

O marco da quebra do paradigma desenvolvimentista da política externa foi a ascensão de Collor à Presidência e a adoção do neoliberalismo como pilar da gestão do Estado nacional, e o alinhamento com o receituário do neoliberalismo mundial. Essa reversão política não se fez sem críticas. $\mathrm{Na}$ mudança de rumos, parecia que o fim do consenso de Tancredo sobre a política externa era inevitável. Começa a emergir acusações de adoção acríticas de ideologias, sem a percepção dos ganhos para a construção do interesse nacional brasileiro.

O pensamento político acerca da política externa não era mais homogêneo. De um lado, acadêmicos reafirmavam certo amadorismo e distanciamento do MRE na condução da política externa. O principal crítico da política externa de Collor foi o diplomata Paulo Nogueira Batista, o qual acreditava que a política externa "collorida" tratava 
[...] de revogar a política de industrializaçâo substitutiva de importaçôes, iniciada por Vargas, prosseguida por Juscelino e confirmada por Geisel, a qual, apesar de baseada na importação de energia, capitais e tecnologia, era vista como buscando objetivos autárquicos através de estatização da economia [...] [além do fato do] Ministério das Relaçóes Exteriores não participar ativamente da formulação da política externa de Collor nem foi tampouco o seu principal executor (BATISTA, 1993, p. 211, grifo nosso).

Em consonância crítica, os acadêmicos reforçavam a politização pelo questionamento do tradicional papel decisório do Itamaraty. Para Hirst e Pinheiro (1995) o projeto de voo curto de Collor colocou o consenso em debate, e esse rompeu com a noçáo consagrada de que continuidade e consenso constituíam aspectos invioláveis da política internacional do país.

Cervo (2002), defende que além de haver-se enfraquecido em razão da discordância interna e da prevalência de pensamento externo ao MRE, o Brasil imprimiu desde o início dos anos noventa orientaçóes confusas, até mesmo contraditórias a política exterior, em função, em função principalmente da adoção do paradigma do Estado normal. Ainda segundo o autor, a estratégia tradicional foi posta em dúvida porque se supunha que houvesse desembocado na crise do endividamento, da instabilidade monetária e da estagnação econômica da década de 1980, e que não resistiria diante das transformações da ordem global ao término da Guerra Fria.

Em entrevista a Casaróes (2011), por sua vez, o ex-chanceler Francisco Rezek afirma o respeito às tradições da inserção internacional brasileira, especialmente o primado do direito, que segundo o chanceler se manteve. Nas suas palavras,

[...] eu estava convencido de que na sua frente de política exterior, o Brasil, desde a proclamação da República, ou antes, possivelmente desde a formação do Império, havia guardado fidelidade à ideia do primado do direito nas relaçóes internacionais. Isso nunca mudou. Nunca se abalou em nenhuma circunstância, no regime civil ou no regime militar, [...] Então veja [...], eu assumo a chancelaria do governo Collor, tendo como diretriz dele apenas a fidelidade a aquilo que havia de melhor na nossa politica externa e d̀ abertura (sic) (REZEK, 2011 apud CASARÓES, 2011, p. 143, grifo nosso).

Posterior ao impeachment de Collor e ao governo de Itamar Franco assume Fernando Henrique que impelia como grande tema da política externa brasileira a inserção do país em um sistema marcado pela lógica da globalização. Cardoso (1996 
apud LAFER, 2001) defendia que a globalização significava o aumento do peso das variáveis externas na agenda econômica, e a redução do espaço para as escolhas nacionais, e com isso a "diluição entre o "interno" e o "externo" levava ao questionamento da hipótese de autonomia da política externa em relação à política interna" (LAFER, 2001, p.17). Embora o discurso de FHC sobre a globalização fosse, segundo Cruz (2004), ambíguo, esse, no entender do então presidente, projetava o Brasil para o limiar de uma nova era.

A inserção brasileira, portanto, deveria abandonar os discursos terceiro mundistas, e se inserir na lógica da globalização, que em resumo seria alterar as ações da diplomacia nacional, agora mais voltada para o jogo das grandes potências econômicas participando ativamente dos mecanismos multilaterais do sistema internacional, com a intenção de projetar o poder brasileiro, e transformá-lo em um ator capaz de influenciar a formaçáo da agenda internacional. A resposta para o modelo de relacionamento brasileira com o mundo foi justificada com base no tradicionalismo. De acordo com Lampreia

A resposta básica pode ser encontrada em princípios que tradicionalmente têm orientado a nossa política externa, como os da não intervenção, respeito à autodeterminação, não ingerência em assuntos internos, e solução pacífica de controvérsias. (...) Além desses princípios, a resposta à segunda pergunta envolve outras facetas de nosso comportamento internacional, como a tradição de nos posicionarmos e relacionarmos de modo aberto, transparente, consistente, com genuíno ânimo de diálogo e cooperação. É possível que o abuso retórico tenha desgastado essas expressóes. Para a diplomacia brasileira, no entanto, é motivo de orgulho - e de reconhecimento de parte de nossos parceiros - havermos sabido manter a coerência entre discurso e ação (LAMPREIA, 1998, p. 51, grifo nosso)

Lafer (2001) justificou a reorientação da política externa para o sul da América no governo Fernando Henrique

[...] em função de sua geografia, de sua experiência histórica e da linha de continuidade de sua ação diplomática o Brasil está à vontade e em casa com o componente sul-americano de sua identidade internacional, que é uma 'força profunda', de natureza positiva, na sua política externa (LAFER, 2001, p. 62, grifo nosso).

Cardoso por sua vez justifica a escolha sul-americana com a convicção de que o Brasil 
[...] parece ter compreendido que o seu projeto de desenvolvimento depende fundamentalmente, no plano externo, da rede de ligaçóes que ele soube tecer em razão da sua identidade mais evidente, a sua sulamericanidade- em outras palavras, que o seu devenir está em função do seu ser e que esse ser não poderia se reduzir a uma identidade amorfa com o Terceiro Mundo ou com a "América Latina". Para isso, a diplomacia desempenhou o seu papel, mantendo a tradição: o Brasil, criação da diplomacia, fica um pouco mais próximo de garantir o seu futuro graças a uma tomada de consciência ontológica que foi em parte uma reinvenção diplomática (CARDOSO apud DANESE, 2001, p. 68, grifo nosso).

O modelo, por sua vez, também não deixou de ser questionado pela elite política e acadêmica brasileira. As principais críticas se reduzem ao fato do aprofundamento da matriz neoliberal na política externa, em decorrência da aplicação das duas gerações de reformas sugeridas pelo Consenso de Washington.

Para Cervo (2002) o Brasil desistiu de fazer política internacional própria, no momento no qual o Brasil aplicou as duas geraçóes de reformas do Consenso de Washington. Segundo o autor

[...] a emergência do Estado normal - subserviente, destrutivo e regressivo - nas estratégias de relações internacionais do Brasil teve como impulso conceitual a idéia de mudança. Não se trata de uma leviandade mental, mas de uma convicção profundamente arraigada na mentalidade de dirigentes brasileiros, capaz de provocar: a) o revisionismo histórico e a condenação das estratégias internacionais do passado; [...] Desistindo de fazer política internacional própria, o Brasil aplicou as duas geraçôes de reformas sugeridas pelo chamado Consenso de Washington (CERVO, 2002, p. 8, grifo nosso).

Para Bernal-Meza (2002), 
Em síntese, a política exterior brasileira foi se adaptando aos novos condicionamentos e cedendo a determinadas pressóes que implicaram mudanças em alguns elementos de sua tradição, como é o caso da adscrição ao princípio de "não intervenção" ou a incorporação de temas da agenda internacional que haviam sido rejeitados no passado, como os direitos humanos, meio ambiente, a mudança de posição relativa à abertura de novas rodadas de negociação comercial no GATT e a estratégia de reforçar o apoio ao Conselho de Segurança da ONU, abandonando sua tradicional política passiva e opositora, posição que tinha se baseado em uma interpretação crítica a respeito dos processos decisórios da organização (BERNAL-MEZA, 2002, p. 61, grifo nosso).

Por mais que a política externa do governo Fernando Henrique tenha posicionado a imagem do Brasil como um ator influente no cenário internacional, principalmente pela noção do Brasil como um global trader, se adequando às condições de uma globalização assimétrica, as consequências das políticas de cunho neoliberais conduziram, no âmbito interno, a um grande desconforto da população em relação ao governo. A resposta da sociedade se confirmaria na eleição do Presidente Lula, nas eleições de 2002, candidato que se elegeu sob a bandeira da mudança socioeconômica nas políticas públicas brasileiras, entre elas a política externa.

Segundo Miyamoto (2011), a política externa vinha carregada de interrogações, inclusive sobre a conduta do país nas negociações econômicas, no cumprimento das obrigaçôes assumidas pelo governo anterior, na (re) definição das parcerias tradicionais, e nas instâncias multilaterais.

Embora para Vigevani e Cepaluni (2007) a política externa de Lula, em comparação com a de FHC, apresentou, como sugeriu Lafer (apud VIGEVANI E CEPALUNI, 2007) mudanças dentro da continuidade essa não foi eximida de críticas em função de uma possível ruptura com as tradições brasileiras. Segundo Barbosa (2009),

Além de seguir duas diferentes orientações, a diplomacia do governo do presidente Lula tem cometido erros grosseiros que ferem uma tradição de bom senso que sempre prevaleceu no Itamaraty. O maior deles é a partidarização de açôes. Com isso, apoiar candidatos a presidente de outros países, como ocorreu nas eleições da Venezuela, Bolívia e Equador. Ao fazer isso, o Executivo está violando as tradiçóes do Itamaraty de jamais interferir na decisão interna de outros países. Forçar a entrada da Venezuela no Mercosul por questóes ideológicas é outra (BARBOSA, 2009 apud BRANCO, 2009, grifo nosso). 
De acordo com Lafer (2009),

A política externa tende a ser, no Brasil e em outras naçōes, uma política de Estado, e não de governo ou de partido - como vem ocorrendo na Presidência Lula -, em função de certas regularidades da inserção internacional de um pais. Essas regularidades contribuem para dar, com as adaptações devidas à mudança das circunstâncias, uma dimensão de continuidade à ação diplomática No caso do Brasil são exemplos esclarecedores de regularidades: a localização geográfica na América do Sul; a menor proximidade dos focos de tensão presentes no cenário internacional; a escala continental que dá relevância ao nosso país na vida internacional; a importância de um pacífico relacionamento com dez vizinhos; a natureza do contexto regional latino-americano, que é distinto de outros; os cuidados no gerenciamento da forte presença dos EUA nas Américas e no mundo; as realidades das assimetrias de poder; o desafio do desenvolvimento (LAFER, 2009, p. A2, grifo nosso).

\section{Schelp (2010) condena a açáo internacional do Governo Lula,}

[...] em governos anteriores, as decisóes nessa área levavam em conta o conhecimento técnico dos diplomatas de carreira, a tradição brasileira e os principios universalmente consagrados da convivência pacífica entre os povos. Essa tradição foi rompida ao se delegar a política externa aos humores dos radicais esquerdistas (SCHELP, 2010, p. 53, grifo nosso).

\section{Segundo Cardoso (2010) as relações exteriores brasileiras}

[...] sempre foram orientadas por valores e estiveram intransigentemente fincadas no terreno do interesse nacional. A demagogia presidencial não passa de surto de ego deslumbrado, que desrespeita os fatos e mesmo a dignidade do país. Com exceção dos flertes com o totalitarismo europeu durante o Estado Novo, sempre nos orientamos pela defesa dos valores democráticos, pela busca da paz entre as naçôes, por sua igualdade jurídica e pela defesa de nossos interesses econômicos (CARDOSO 2010, p. 1, grifo nosso).

Em contrapartida, o então Assessor Internacional do Brasil Marco Aurélio Garcia justifica que 
[...] a politica externa do governo Lula e da nova presidenta resgatou valores que inspiraram os grandes momentos de nossa tradição diplomática: o respeito à soberania nacional e a não intervenção nos assuntos internos de outros países, a luta pela paz e pela solução política de conflitos, a defesa da democracia e dos direitos humanos, o multilateralismo. A essa agenda foram acrescidos (ou nela enfatizados) temas como o do combate à fome e à exclusão social no mundo, o que implicou a defesa de uma ordem econômica global mais justa (GARCIA, 2011, p. 2, grifo nosso).

Amorim e Feldman (2011) buscam na reafirmação das tradições legitimar a política externa do Governo Lula, segundo os diplomatas,

$\mathrm{Na}$ orientação geral e na determinação e intensidade com que seus objetivos foram perseguidos, nossa diplomacia retomou sua ênfase em autonomia e pluralismo. [...] . À medida que o governo passou das enunciaçóes iniciais para açóes concretas, a atitude e o escopo da diplomacia revelaram elementos da linhagem consolidada por Rui Barbosa e San Tiago Dantas. (AMORIM e FELDMAN, 2011, p. 283, grifo nosso)

Como tentado demonstrar, as grandes discussões sobre a política sempre buscaram se respaldar na busca recorrente das tradições nacionais, fato que por si só não nos permite concluir que exista no Itamaraty somente uma corrente de tradição. O problema está para além desse questionamento. Embora possamos encontrar no processo de construção da memória institucional certos padrões de regularidade, ao longo da história nacional os mesmos indícios tradicionais, nos levam a crer que a tradição não é utilizada da mesma forma por aqueles que participam das discussões da PEB.

\section{Conclusões: Para o bem e para o mal}

Nossas conclusões perpassam às de Francisco (2010) que defende que a ideia de tradição, enquanto parte da dinâmica de produção e atualização da memória institucional, contribui para que a história produzida a partir do Itamaraty seja percebida como a principal vertente de uma história da política externa brasileira, na qual a importância se estende dos mitos fundacionais remetidos à Primeira República, até o debate político contemporâneo em que a ideia de tradição é manipulada.

Concordamos também com Garcia (2001), o qual defende que a política externa, como toda política, sempre dividiu e divide uma sociedade, salvo em momentos muito especiais, como os de graves ameaças forâneas. Isso porque a 
política externa - como a econômica, a social e tantas outras - expressa interesses, sociais e políticos distintos, e percepções culturais diversas.

A tradição na política externa atende aos dois lados da disputa política. Com a tentativa de reafirmar ou enfraquecer a escolha política a tradição é colocada em discussão. Cabe salientar que acreditamos que a história da política externa foi escrita de acordo com os interesses dos grupos que possuem o poder decisório, e esses valores e ideias são reformulados e renovados, na melhor tradição itamaratiana para responder aos anseios desses projetos.

Nesse sentido, a observação permite concluir que aqueles que buscaram interferir no debate da política via utilização das tradiçóes, o fez de acordo com seus propósitos políticos dentro de duas chaves possíveis. A tradição diplomática foi utilizada tanto para defender quanto para atacar.

Quando utilizada para defender opçóes políticas, a política externa foi baseada em um discurso tradicionalista com a intenção, a nosso ver, de despolitizar um possível debate em torno da questão. A justificativa dos movimentos políticos, mesmo os de mudança, sempre estiveram bem assentados em discursos tradicionalistas, vide o discurso dos chanceleres da Política Externa Independente, na adoção do neoliberalismo, e durante o governo Lula.

Pelo outro lado, quando grupos contrários à política externa colocada em prática buscam o seu questionamento, esses em geral invocam o discurso do náo respeito às tradições por parte do governo, ou seja, é também pela politização da tradição que os grupos opositores conseguem participar da discussão da política externa brasileira.

Nada mais simples e lógico do que acreditar que mesmo que o Itamaraty projete uma tradição una, o que percebemos é a existência de, se não várias tradições, ao menos a utilização de alguns princípios tradicionais em detrimento de outros.

- Lucas Ribeiro Mesquita é Professor do Curso de Ciência Política e Sociologia da Universidade Federal da Integração LatinoAmericana (UNILA) e Doutorando em Ciência Politica pela UFMG. E-mail: lucas.mesquita@unila.edu.br. 


\section{Referências}

ALMEIDA, Paulo Roberto. Formaçâo da diplomacia econômica no Brasil: as relaçóes econômicas internacionais do Império. São Paulo: Editora Senac-Funag, 2008.

ALMEIDA, Paulo Roberto. O legado do Barão: Rio Branco e a moderna diplomacia brasileira. Rev. Bras. Polit. Int. v. 39, n. 2, p.125-135, 1996.

AMORIM, Celso. A diplomacia multilateral do Brasil: um tributo a Rui Barbosa. Brasília: Ipri/Funag, 2007.

AMORIM, Celso; FELDMAN, Luís. A política externa do governo Lula em perspectiva histórica. In: DANTAS, San Tiago. Política externa independente. Brasília: Fundação Alexandre de Gusmão, 2011.

AZEVEDO, Ricardo; FERNANDES, Tiago. Nabuco e a Construição do Pan-Americanismo. In: CHDD. Centro de História e Documentação Diplomática. Joaquim Nabuco, Embaixador. Vol. 1. Brasília: FUNAG, 2011.

BATISTA, Paulo Nogueira. A Política Externa de Collor: modernização ou retrocesso? Política Externa, vol. 1, n. 4,1993.

BERNAL-MEZA, Raúl. A política exterior do Brasil: 1990-2002. Rev. Bras. Polit. Int. Brasília, v. 45, n. 1, p. 36-71, jan./jul. 2002.

BRANCO. Renata. Rubens Barbosa: Governo partidarizou o Itamaraty. Agência Tucana, 30 out. 2009. Disponível em: <http://www.psdb.org.br/index.php/agencia-tucana/noticias/rubensbarbosa-governo-partidarizou-o-itamaraty>. Acesso em: 14 dez. 2011.

BUERE, Júlio. O Itamaraty e a Tradição. In: $A B R I$ - Encontro Nacional da Associação Brasileira de Relações Internacionais, 3, São Paulo, 2011.

BURNS, Edward B. The unwritten alliance. Nova Iorque.Columbia University Press. 1966.

CARDIM, Carlos H. A raiz das coisas - Ruy Barbosa: o Brasil no mundo. Rio de Janeiro: Civilização Brasileira, 2007.

CARDOSO, Fernando H. Discurso em Razão das Comemoraçôes do Dia do Diplomata. Brasília. 20 abr. 1993.

CARDOSO, Fernando H. Por uma politica externa responsável. Instituto Teotônio Vilela, 6 jun. 2010. Disponível em: < http:/www.psdbnacamara.com.br/wordpress/?p=2177>. Acesso em: 20 de ago de 2014

CASARÓES, Guilherme. As três camadas da politica externa do governo Collor: poder, legitimidade e dissonância. 2011. 186p. Dissertação (Mestre em Relaçôes Internacionais) - Programa de PósGraduação em Relaçôes Internacionais San Tiago Dantas, Universidade Estadual de Campinas, Campinas, 2011.

CERVO, Amado L. Relaçôes internacionais do Brasil: um balanço da era Cardoso. Rev. Bras. Polit. Int., Brasília, n. 2, p. 5-35, jan./jul. 2002.

CERVO, Amado L.; BUENO; Clodoaldo. História da Politica Exterior do Brasil. Brasília: UnB, 2002.

CHEIBUB, Zairo. Diplomacia, diplomatas e politica externa: aspectos do processo de institucionalização do Itamaraty. 1984. 140p. Dissertação (Mestrado em Ciência Política) Instituto Universitário de Pesquisas do Rio de Janeiro, Rio de Janeiro, 1984.

CRUZ, Sebastiẫo. Globalização, democracia e ordem internacional: Ensaios de teoria e história. Campinas: Editora da Unicamp, 2004.

DAMATTA, Roberto. Carnavais, malandros e heróis: para uma sociologia do dilema brasileiro. Rio de Janeiro: Rocco, 1997. 
DANESE, Sérgio. O Brasil e a América do Sul: Apontamentos para a história de uma convergência. Politca Externa, v. 9, n. 4, p. 41-71, 2001.

DANTAS, San Tiago. Discurso de posse do ministro das Relaçóes Exteriores, Francisco Clementino de San Tiago Dantas - 11 de setembro de 1961. In: FRANCO, Alvaro da Costa (Org.). Documentos da politica externa independente. V.1. Brasília: Funag, 2007.

DOUGLAS, Mary. Como as instituiçōes pensam? São Paulo: EDUSP, 1998.

FRANCISCO, Paula E. V. Continuidade e mudança na história intelectual diplomática brasileira: uma análise da construção da tradição. 2010. 203 f. Dissertação (Mestrado) - Instituto de Relaçóes Internacionais, Pontifícia Universidade Católica do Rio de Janeiro, 2010.

FRANCO FILHO, Afonso A. Diplomacia Independente - Um Legado de Afonso Arinos. São Paulo: Paz e Terra, 2001.

GARCIA, Marco Aurélio. Respostas da Política Externa Brasileira às Incertezas do Mundo Atual. Interesse Nacional, São Paulo, vol. 13, p. 1-10, abr./jun. 2011.

GARCÍA, Marco Aurélio. O melancólico fim de século da política externa. Carta Internacionaı, $\mathrm{n}^{\circ}$ 94/95, p. 6-7, dez. 2000/jan. 2001.

GOFFREDO Jr., Gustavo. Tradição, normas e a politica externa brasileira para os direitos humanos. 2000. 139p. Dissertação (Mestrado em Relações Internacionais) - Instituto de Relações Internacionais, Pontifícia Universidade Católica do Rio de Janeiro, Rio de Janeiro, 2000.

HALBWACHS, Maurice. La mémoire collective. Paris: Albin Michel, 1997.

HIRST, Monica; PINHEIRO, Letícia. A Política Externa do Brasil em dois tempos. Rev. Bras. Polit. Int, Brasília, vol. 38, no. 1, p. 5-24, 1995.

HOBSBAWM, Eric. Introdução: A Invenção das Tradiçôes. In: HOBSBAWM, Eric.; RANGER, Terence (Orgs.). A invenção das tradiçóes. Rio de Janeiro: Paz e Terra, 1997. p. 9-23.

LAFER, Celso. A Identidade Internacional do Brasil e a Politica Externa Brasileira: passado, presente e futuro. São Paulo: Perspectiva, 2001.

LAFER, Celso. Partidarização da política externa. O Estado de S. Paulo, p. A2, 20 dez. 2009.

LAMPREIA, Luiz F. A política externa do governo FHC: continuidade e renovação. Rev. Bras. Polít. Int., Brasília, v. 41, n. 2, 5-17, jul./dez. 1998.

LOPES, Dawisson. A política externa brasileira e a 'circunstância democrática': do silêncio respeitoso à politização ruidosa. Rev. Bras. Polit. Int., v. 54, n. 1, p. 67-86, jul. 2011.

MARIANO, Marcelo. A Política Externa Brasileira, o Itamaraty e o Mercosul. 2007. 218p. Tese (Doutorado em Sociologia) - Programa de Pós-Graduação em Sociologia, Universidade Estadual Paulista Júlio de Mesquita Filho, Araraquara, 2007.

SILVA, Alexandra de Mello e. O Brasil no Continente e no Mundo: atores e imagens na política externa brasileira contemporânea. Estudos Históricos, vol. 8, n. 15, p. 95-118 1995.

MISZTAL, Barbara. Theories of social remembering. Philadelphia: McGraw-Hill International, 2003.

MIYAMOTO, Shiguenoli. A política externa do governo Lula: Aspiraçóes e dificuldades. Idéias, Campinas, v. 1, n. 3, p. 119-132, 2011.

MOURA, Cristina P. de. Herança e Metamorfose: a Construção Social de dois Rio Branco. Revista Estudos Históricos, Rio de Janeiro, v. 14. n. 25, p. 81-102, 2000.

MOURA, Cristina P. de. O Instituto Rio Branco e a Diplomacia Brasileira - Um Estudo de Carreira e Socialização. Rio de Janeiro: Ed. FGV, 2007.

NABUCO, Joaquim. A aproximação das duas Américas. In: MELLO, Evaldo. Joaquim Nabuco Essencial. Penguin, 2010. [1909]. 
RENOUVIN, Pierre; DUROSELLE, Jean B. Introdução à história das relaçôes internacionais. São Paulo: Difusão Europeia do Livro, 1967.

SANTOS, Luís C. V. G. A América do Sul no discurso diplomático brasileiro. Rev. Bras. Polit. Int., Brasília, v. 48, n. 2, p. 185-204, dec. 2005.

SCHELP, Diogo. Bandeiras Ideológicas. Revista Veja, ed. 2151, p. 52-53, 10 fev. 2010.

SOARES, Álvaro T. Organização e administração do ministério dos estrangeiros. Brasília: Funcep, 1984.

VARGAS, Getúlio. Brasil e as suas forças armadas nas tarefas árduas da guerra. 05 jan. 1952. Discurso pronunciado em almoço de confraternização das forças armadas. Disponível em: <http://www.biblioteca.presidencia.gov.br/ex-presidentes/getulio-vargas/discursos-1/1943/24.pdf>. Acesso em: 21 jul. 2014.

VIGEVANI, Tullo; CEPALUNI, Gabriel. A política externa de Lula da Silva: a estratégia da autonomia pela diversificação. Contexto internacional, Rio de Janeiro, v. 29, n. 2, 273-335, jul./dez. 2007. 